\title{
Insect Cardioactive Peptides: Cardioacceleratory Peptide (CAP) Activity Is Blocked In Vivo and In Vitro with a Monoclonal Antibody
}

\author{
Nathan J. Tublitz and Peter D. Evans \\ AFRC Unit of Insect Neurophysiology and Pharmacology, Department of Zoology, University of Cambridge, \\ Cambridge CB2 3EJ, United Kingdom
}

\begin{abstract}
We demonstrate here that a specific monoclonal antibody can be utilized as a physiological tool to analyze neuropeptide function. Two cardioacceleratory peptides (CAPs) have been recently isolated from the CNS of the tobacco hawkmoth, Manduca sexta (Tublitz and Truman, 1985a), and it has been suggested that they act as cardioregulatory neurohormones during adult emergence and wing inflation (Tublitz and Truman, 1985b). Evidence is presented here indicating that a monoclonal antibody, 6C5, selectively and specifically precipitated the biological activities of both CAPs. In vivo injections of 6 C5 markedly reduced CAP hemolymph titers in newly emerged adults. The $6 \mathrm{C5}$ treatment also blocked the primary physiological effect of the CAPs, the increase in cardiac activity seen during adult wing expansion. In addition, removal of the postemergence CAP pulse with $6 \mathrm{C5}$ prolonged the duration of wing-inflation behavior. Thus, by neutralizing CAP hemolymph activity with a CAPspecific antibody, we have shown that the CAPs are involved in cardioregulation in newly emerged moths.
\end{abstract}

Neuropeptides are utilized by the nervous system in a variety of physiological processes, in which they act as neurotransmitters (Adams and O'Shea, 1983; Jan and Jan, 1982; Konishi et al., 1981; Lundberg et al., 1979; Takahashi et al., 1974), neuromodulators (Abrams et al., 1984; Brownell and Mayeri, 1979; Kreiger et al., 1983; Lloyd et al., 1984; Mayeri and Rothman, 1982), and neurohormones (Guillemin, 1978; Kupfermann, 1970; Lloyd, 1978; Pfaff, 1973; Truman, 1980). Yet unequivocal identification of a functional role for many peptides remains elusive because of the stringent physiological, pharmacological, and anatomical criteria that must be met (Barker, 1977), many of which are similar to those used in the identification of conventional neurotransmitters (Werman, 1966). One condition that is seldom met is that the absence of the neuropeptide under investigation prevents the onset of the proposed physiological response. Attempts at satisfying this criterion for neurotransmitters other than neuropeptides have usually utilized pharmacologically similar compounds that act as antagonists by binding to a membrane-bound receptor (Evans, 1981; Langer, 1980). In the case of neuropeptides, such experiments have generally not been possible due to the lack of a compound that specifically blocks the peptide receptor (Hanley, 1982). One possible solution to this dilemma often used by neuroendocri-

Received Nov. 20, 1985; revised Jan. 20, 1986; accepted Jan. 24, 1986.

We wish to thank Dr. Paul H. Taghert for his generous donation of the monoclonal antibodies used in this study. We are grateful to Drs. S. Laughlin and S. H. P. Maddrell for critically reviewing earlier drafts of this manuscript. This work was supported by a British-Amcrican Rescarch Fellowship granted under the auspices of the American Heart Association and British Heart Foundation to N.J.T.

Correspondence should be addressed to Dr. Nathan J. Tublitz, Institute of Neuroscience, University of Oregon, Eugene, OR 97403.

Copyright (C) 1986 Society for Neuroscience $0270-6474 / 86 / 082451-06 \$ 02.00 / 0$ nologists is to extirpate the tissue responsible for the synthesis and/or release of the neuropeptide. Unfortunately, this procedure is not always feasible in many neurosecretory systems because of anatomical considerations or because of the diffuse nature of the neurohemal release site. We have taken a different approach to this problem, and in this report we show that neuropeptide effects can be blocked in vivo and in vitro through the use of a specific monoclonal antibody.

We have been investigating this problem in relation to the action of the cardioacceleratory peptides (CAPs) in the tobacco hawkmoth, Manduca sexta (Tublitz, 1983). Two cardioacceleratory neuropeptides, known as cardioacceleratory peptide $\left(\mathrm{CAP}_{1}\right)$ and cardioacceleratory peptide ${ }_{2}\left(\mathrm{CAP}_{2}\right)$, have been physiologically localized to individually indentifiable neurons in the ventral nerve cord (VNC) of the pharate adult moth (Tublitz and Truman, 1985a, c, d). The CAP-containing neurons project to and terminate in blind neurohemal endings along the segmentally repeated perivisceral organs (PVOs). The PVOs are the primary neurohemal release site of the insect VNC and in Manduca are located on each of the abdominal and thoracic transverse nerves. Previous reports (Tublitz and Truman, 1985b) suggested the possibility that the CAPs might act as cardioregulatory neurohormones during adult wing-spreading (WS) behavior, facilitating the inflation of the adult wings by markedly increasing the heartbeat. This conclusion was based on several lines of evidence, much of which was indirect and of a correlative nature. The experiments presented here represented an attempt to verify the above conclusion using a more direct, empirical approach.

\section{Materials and Methods}

In vitro Manduca heart bioassay

CAP bioactivity was measured using an isolated Manduca heart bioassay as previously described (Tublitz and Truman, 1985a). In short, a portion of the abdominal heart was removed from a pharate adult male, pinned into a small superfusion chamber, and attached to a force transducer (Bionix F-200 Isotonic Displacement Transducer powered by a Bionix Powerpack Ed-1A). The signal from the transducer was amplified and fed through a window discriminator and digital-to-analog converter to measure instantaneous heart rate. Normal Manduca saline was used for all experiments (Tublitz and Truman, 1985a, b).

\section{Immunoprecipitation}

Equal aliquots of $\mathrm{CAP}_{1}$ or $\mathrm{CAP}_{2}$ purified by high-pressure liquid chromatography (HPLC) were incubated for $30 \mathrm{~min}$ at $0^{\circ} \mathrm{C}$ in Manduca saline (Tublitz and Truman, 1985a, b) either alone or in the presence of antibodies $6 \mathrm{C} 5$ or $2 \mathrm{C} 7$ at a dilution of 1 part antibody: 10 parts saline. All but 1 aliquot then received an excess of $S$. aurenus (Cowen strain) whole cells $(10 \mathrm{mg} / \mathrm{ml})$ containing Protein A (Sigma). After a second $30 \mathrm{~min}$ incubation at $0^{\circ} \mathrm{C}$, each aliquot was spun in a microfuge (MSE MicroCentaur) at $12,000 \times g$ for $5 \mathrm{~min}$ and the supernatant bioassayed on the isolated pharate adult Manduca heart as previously described (Tublitz and Truman, 1985a, b). 

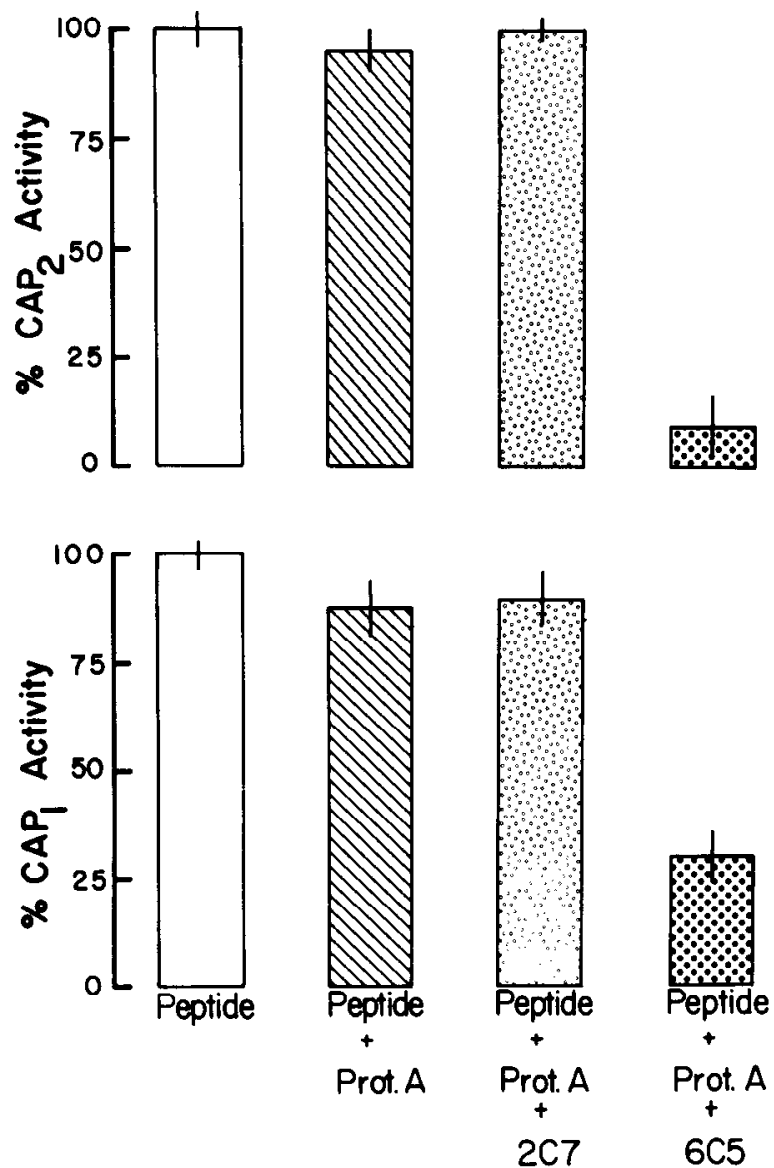

Figure 1. Immunoprecipitation of $\mathrm{CAP}_{1}$ and $\mathrm{CAP}_{2}$ activity by antibody $6 \mathrm{C} 5$. Antibody $2 \mathrm{C} 7$ nonspecifically stains all neurons in the Manduca CNS (Taghert et al., 1983; P. Taghert, personal communication) and was used as a control in these experiments. Activity is expressed as a percentage of peptide activity remaining compared to the untreated (Peptide) controls. Error bars on the untreated controls refer to the variability between individual samples. No measurable loss of peptide activity was measured in the untreated controls. Each bar represents the mean \pm SEM of at least 5 separate determinations.

\section{CAP purification}

The abdominal portions of the ventral nerve cord (ANC) were removed from pharate adults and stored at $-20^{\circ} \mathrm{C}$. A few phenylthiourea crystals were added to the frozen tissues to prevent melanization by endogenous tyrosinases (Williams, 1959). Tissues were homogenized in a small ground-glass homogenizer containing $100 \%$ methanol at least 5 times greater than the wet weight of the tissue. The homogenate was centrifuged for $5 \mathrm{~min}$ at approximately $12,000 \times g$ in a microfuge. The resultant supernatant was diluted 1:1 with double-distilled water and lyophilized. The dried sample was resuspended in double-distilled water and applied to a Waters C-18 Sep-pak. $\mathrm{CAP}_{1}$ and $\mathrm{CAP}_{2}$ activities were eluted with $80 \%$ acetonitrile, freeze-dried, resuspended, and applied to a reverse-phase HPLC C-18 column. A linear water-acetonitrile gradient separated $\mathrm{CAP}_{1}$ from $\mathrm{CAP}_{2}$, and final purification was achieved by eluting under isocratic conditions.

\section{In vivo heart activity}

Continuous in vivo heart recordings from intact pharate adult and adult Manduca were obtained using an impedance converter (Biocom Corp., Model 2991) as previously described (Tublitz and Truman, 1985b). The heart of the device is a load-sensitive $50 \mathrm{kHz}$ oscillator that converts an impedance change at the recording electrodes into an output voltage (Miller, 1973). The leads from the impedance converter were inserted into 2 holes that had been made in a descaled portion of the metathoracic medial scutellar plate and fixed into place on either side of the heart

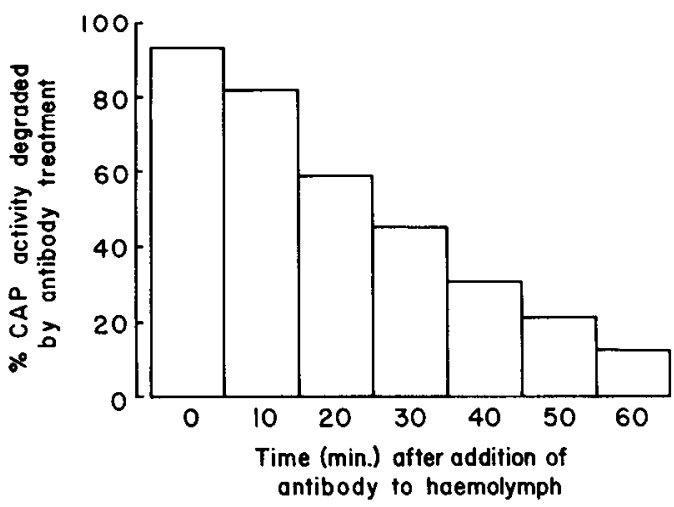

Figure 2. Kinetics of antibody degradation in Manduca hemolymph. The antibody $6 \mathrm{C} 5$ was incubated in pharate adult hemolymph for various times and then tested for its ability to precipitate $\mathrm{CAP}_{2}$ activity. Data are presented as a percentage of CAP activity inactivated by antibody treatment compared to controls containing no antibody. Each histogram represents the mean of 2 determinations.

using beeswax. The signal from the impedance converter was amplified and recorded onto a Rickadenki chart recorder for subsequent analysis. After electrode implantation, animals were placed inside a small wire mesh container that permitted in vivo heart recordings to be taken during eclosion and WS behaviors (Tublitz and Truman, 1985b).

\section{In vivo antibody injections}

Pharate adult males were monitored throughout the final day of adult development and were chosen for these experiments only after they had entirely resorbed their molting fluid. At this developmental stage, the pupal cuticle was extremely dry and brittle, indicating that adult emergence was imminent. Each animal then received a $100 \mu \mathrm{l}$ injection from a Hamilton syringe of either antibody $6 \mathrm{C5}$ or mouse serum dissolved in Manduca saline, resulting in an in vivo hemolymph antibody dilution of approximately $1: 10$. Controls received injections of the saline carrier. Occasionally the physical manipulation of the injection procedure was sufficient to induce eclosion, but usually it was necessary to remove gently the pupal cuticle around the head to ensure the intiation of adult ecdysis after antibody application. Because the results from experiments described in Figure 2 indicated that the antibody was degraded in vivo by the hemolymph within $30 \mathrm{~min}$, animals received antibody booster injections (1:10 final antibody dilution) every half-hour. There was no apparent effect of repeated saline injections on the duration or quality of eclosion and WS behaviors (Fig. 5).

For the in vivo heart recording experiments, initial and booster injections of either antibody $6 \mathrm{C} 5$ or mouse serum were applied according to the protocol described above, except that great care was taken not to induce premature eclosion by the injection procedure. As before, boosters were administered at $30 \mathrm{~min}$ intervals.

\section{CAP hemolymph titers}

CAP titers were determined by collecting hemolymph at various times after eclosion and bioassaying for CAP activity on the in vitro pharate adult Manduca heart as previously described (Tublitz and Truman, $1985 \mathrm{a}, \mathrm{b})$. In short, hemolymph was obtained by inverting a decapitated animal into an ice-cold glass vial. After collection, hemolymph was heat-treated at $80^{\circ} \mathrm{C}$ for $5 \mathrm{~min}$ and centrifuged in a microfuge at $12,000 \times$ $g$ for $3 \mathrm{~min}$. The supernatant was then removed and either bioassayed immediately or stored at $-20^{\circ} \mathrm{C}$ for later testing.

\section{Results}

\section{Immunoprecipitation of CAP activity}

As previously detailed, monoclonal antibodies directed against the CAPs were raised in mice using 3000 pharate adult PVOs as the primary antigenic source (Taghert et al., 1983). After isolation and immortalization of individual clones, each antibody was histologically screened on the Manduca CNS (Taghert et al., 1983). Those antibodies that proved positive in the his- 


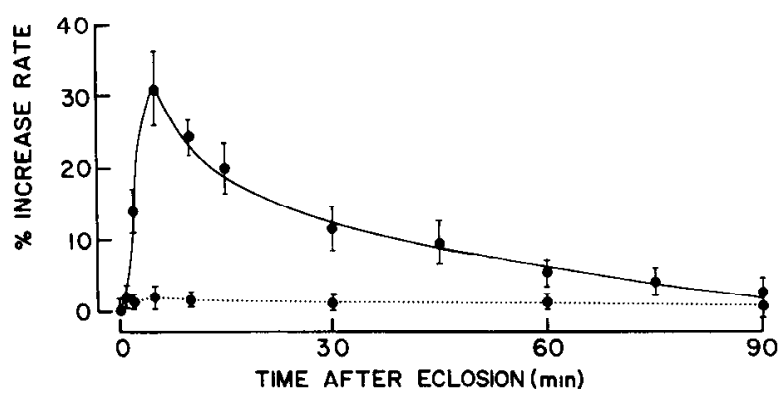

Figure 3. Effect of antibody $6 \mathrm{C} 5$ on the CAP hemolymph titer during eclosion and WS in the tohacco hawkmoth, $M$. sexta. Data are expressed as a percentage increase in basal heart rate. Each point indicates the mean \pm SEM of at least 6 separate determinations. Time 0 represents samples taken within a few seconds after the successful completion of ecdysis. Dotted curve, $6 \mathrm{C} 5$ treatment; solid line, mouse serum.

tological assay were further tested for specificity using both enzyme-linked immunosorbent assay (ELISA) and biological assay systems (Taghert et al., 1984; Taghert and Tublitz, unpublished observations). With the recent development of a purification procedure for both CAPs, one of the putative anti-CAP antibodies, $6 \mathrm{C} 5$, was tested for its ability to precipitate HPLCpurified CAP ${ }_{1}$ and CAP $_{2}$ bioactivity. As shown in Figure 1, the bioactivity levels of both CAPs were markedly reduced in the presence of the $6 \mathrm{C} 5$ antibody. The antibody showed a relatively greater preference for $\mathrm{CAP}_{2}$ than for $\mathrm{CAP}_{1}$. CAP levels were relatively unaffected in those aliquots containing either Protein A alone or another monoclonal antibody (2C7) derived from the same fusion. The $6 \mathrm{C5}$ antibody did not immunoprecipitate the biological activities of biogenic amines, 5-HT, or octopamine, nor 2 known insect peptide hormones, eclosion hormone and bursicon.

\section{Kinetics of antibody degradation in the hemolymph of Manduca}

To determine the functional lifetime of $6 \mathrm{C} 5$ activity in the hemolymph, antibody was incubated at $0^{\circ} \mathrm{C}$ in whole blood extracted from pharate adults. This developmental stage was chosen because it was previously demonstrated that pharate adult hemolymph contained no detectable amount of either $\mathrm{CAP}_{1}$ or $\mathrm{CAP}_{2}$ (Tublitz and Truman, 1985b). At various times after the addition of antibody, aliquots of hemolymph were removed and incubated with a small amount of HPLC-purified $\mathrm{CAP}_{2}$ for 10 min at $0^{\circ} \mathrm{C}$. Each sample was immunoprecipitated using the procedure described in Materials and Methods and the resultant supernatant bioassayed for CAP activity.

The ability of the antibody $6 \mathrm{C} 5$ to bind to $\mathrm{CAP}_{2}$ was inversely proportional to the amount of time the antibody was incubated in pharate adult hemolymph (Fig. 2). $6 \mathrm{C5}$ immunobinding activity slowly declined in a linear fashion over the 60 min testing period. The functional half-life of $6 \mathrm{C5}$ in the hemolymph was approximately $30 \mathrm{~min}$. These results were taken into account in all subsequent experiments that required prolonged antibody exposures.

\section{Effect of antibody treatment of CAP hemolymph titers}

The $6 \mathrm{C} 5$ antibody was injected in vivo into pharate adults just prior to adult emergence to investigate its effects on the rise in the CAP hemolymph titer normally seen immediately after adult emergence (Tublitz and Truman, 1985b). Animals treated with 6C5 did not exhibit the characteristic increase in CAP hemolymph levels (Fig. 3). Their levels remained close to basal throughout the 90 min following adult ecdysis, during which time the adult wings are inflated. In contrast, CAP titers were

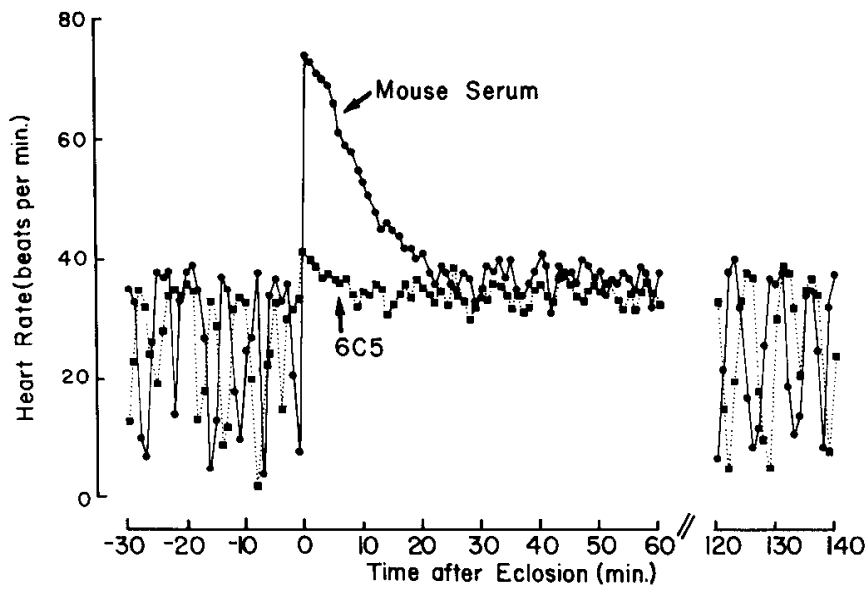

Figure 4. Effect of antibody $6 \mathrm{C} 5$ on in vivo heart rate during eclosion and WS in the tobacco hawkmoth, $M$. sexta. As described earlier (Tublitz and Truman, 1985b), the behavior of the heart changes dramatically at eclosion (time 0). A significant increase in heart rate is accompanied by a cessation of heartbeat reversals, a cardiac behavior characterized by periodic changes in beat frequency and direction of flow that occurs routinely during the pharate adult and post-WS stages (Tublitz and Truman, $1985 \mathrm{~b}$ ). Note that $6 \mathrm{C} 5$ treatment dramatically reduces the posteclosion rise in heart rate. Squares, 6C5; circles, mouse serum.

unaffected and followed their normal time course in those animals injected with mouse serum (Fig. 3). In addition, no effect on the posteclosion rise in CAP levels was noticed in those animals treated with the antibody $2 \mathrm{C} 7$, another monoclonal from the same fusion (data not shown).

\section{Effect of antibody treatment on in vivo heart rate}

Having demonstrated that an in vivo injection of the $6 \mathrm{C5}$ antibody was capable of blocking the rise in CAP hemolymph titers immediately following eclosion, we were interested in determining whether $6 \mathrm{C} 5$ treatment also blocked one of the physiological effects of the CAPs, e.g., the posteclosion increase in heartbeat frequency. In these experiments, in vivo heart rate was monitored with an impedance converter. The 6C5 injected animals exhibited only a slight rise in heart rate in vivo following adult emergence (Fig. 4, Table 1), whereas controls treated with mouse serum showed a dramatic posteclosion increase in heartbeat (Fig. 4, Table 1). No measurable difference in maximal heartbeat rate after eclosion was noted between those controls that were injected either with saline or mouse serum (Table 1), and these values did not differ from those obtained with untreated animals (Tublitz and Truman, 1985b). Antibody treatment had no apparent effect on the behavior of the in vivo heart in the pharate adult before adult emergence nor after WS was successfully completed (Fig. 4). These data show that the post-

Table 1. Effect of the monoclonal antibody $6 \mathrm{C5}$ on in vivo heart rate in newly emerged $M$. sexta adults

Treatment

Saline

Mouse serum

$6 \mathrm{C} 5$

Experimental protocol for these experiments is as described in Materials and Methods. Heart rate was continuously measured prior to and throughout eclosion and WS. Maximal heart rate after eclosion was divided by the beat frequency of the heart immediately prior to adult emergence and expressed as a percentage. Each value represents the mean \pm SEM of 6 separate determinations. 


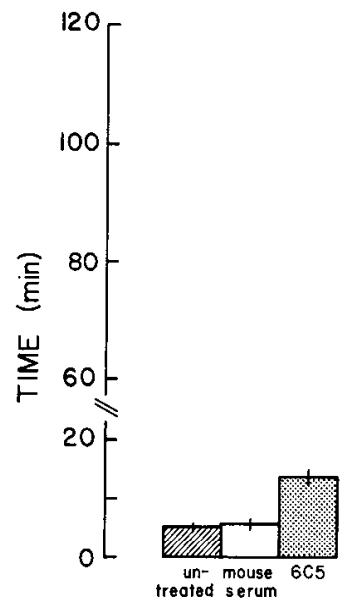

ONSET

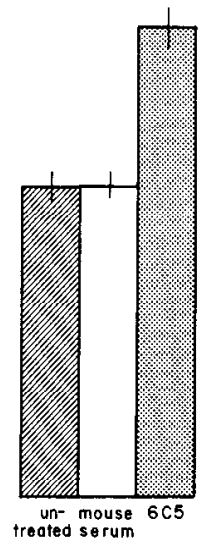

DURATION
Figure 5. Effect of 6C5 injections on the onset and duration of WS behavior in $M$. sexta. Injections were carried out according to the procedure described in Materials and Methods. Antibody and mouse serum blood titers were maintained at a dilution of approximately $1: 10$ relative to hemolymph volume. Onset and Duration refer to the time intervals ( $\min$ ) between adult emergence and the initiation of WS behavior, and from the commencement to the completion of WS, respectively. Untreated controls received no injections. Each value represents the mean \pm SEM of 10 separate determinations.

eclosion rise in heart rate is greatly reduced by the presence of the 6C5 antibody in the hemolymph.

\section{Effect of antibody treatment on the initiation and duration of $W S$ behavior}

We were also interested in ascertaining whether $6 \mathrm{C} 5$ treatment had any significant behavioral effects on adult emergence and WS. Animals injected with $6 \mathrm{C} 5$ eclosed normally and successfully inflated their wings. There were, however, 2 significant behavioral differences, as determined by measuring the time from eclosion to the onset of wing inflation and the total duration of WS behavior, between control and 6C5-treated animals. As shown in Figure 5, the primary effect of the antibody was to extend markedly the time needed to complete WS behavior. Animals receiving $6 \mathrm{C} 5$ injections required $33 \%$ more time to inflate their wings fully in comparison to either uninjected controls or those treated with mouse serum (Fig. 5). In addition, antibody treatment produced a substantial effect on the onset of WS compared to controls treated with mouse serum. Based on observation, other common adult behaviors such as walking, preflight warm-up, and flight appeared to be qualitatively unaffected by the antibody treatment.

\section{Discussion}

\section{Molecular specificity of antibody $6 C 5$}

All of the experimental manipulations of CAP activity described in this paper utilized a monoclonal antibody to specifically block CAP activity in vivo. To interpret the in vivo antibody injection experiments properly, the antibody used in these experiments, $6 \mathrm{C} 5$, was subjected to several tests to determine its molecular specificity.

Earlier work (Taghert et al., 1984; Taghert and Tublitz, unpublished observations) using an ELISA plate assay system indicated that one antibody, 6C5, was capable of binding to both $\mathrm{CAP}_{1}$ and $\mathrm{CAP}_{2}$ that had been partially purified using gel-filtration chromatography. Further experiments using partially purified material suggested that $6 \mathrm{C} 5$ was also able to immu- noprecipitate the biological activities of both CAPs (Taghert et al., 1984). The experiments presented in this paper using HPLCpurified material corroborated our initial findings. 6C5 immunoprecipitated both CAPs, although it appeared to have a greater affinity for $\mathrm{CAP}_{2}$ activity. $6 \mathrm{C} 5$ had no effect on several other known insect cardioregulatory substances, e.g., octopamine and 5-HT, and did not interfere in vitro with the activities of eclosion hormone and bursicon, 2 insect neuropeptides known to be present in the hemolymph of Manduca at the time of CAP release. The fact that the biological activities of both CAPs decreased when incubated with 6C5 suggested that the 2 CAPs share a similar antigenic recognition site. Based on these results, we concluded that the $6 \mathrm{C5}$ antibody is specifically directed against both CAPs.

\section{$C A P_{1}$ and $C A P_{2}$ are cardioregulatory neurohormones}

Inflation and expansion of the wings after adult emergence in Manduca, as in all Lepidoptera, is brought about by a complex series of behavioral and physiological responses (Wigglesworth, 1972). In short, hemolymph is pumped into the wings by the relatively simple insect circulatory system assisted by a large increase in hemocoelic pressure due to a tonic contracture of the abdominal tergosternal muscles. Several investigations have reported that there is a dramatic change in the patterned behavior of the heart during adult emergence and wing inflation (Moreau and Lavenseau, 1975; Tublitz and Truman, 1985b; Wasserthal, 1976).

Since the discovery of the C.APs (Tublitz and Truman, 1980), our working hypothesis on the function of these cardioregulatory neuropeptides has been that one of their actions is to facilitate inflation of the wings by increasing the pumping rate of the circulatory system during this crucial developmental period (Tublitz and Truman, 1985b). The empirical basis underpinning this hypothesis came from several different lines of evidence, described in detail in an earlier publication (Tublitz and Truman, 1985b). To summarize, in vivo heart recordings from pharate and newly emerged adults revealed a marked increase in heart rate associated with WS behavior. Bioassay of whole blood taken from WS animals indicated the presence of 2 blood-borne, cardioacceleratory factors and several biochemical analyses showed that they coeluted with the 2 CAPs. In addition, measurements of blood CAP levels indicated that the peak CAP titers were coincident with the initiation of WS behavior. These data taken together indirectly suggest, but do not prove, a causal relationship between the CAPs and the postemergence increase in heart rate.

The data presented here provide evidence of a more direct nature in support of our working hypothesis. In vivo injections of 6C5 (Fig. 3) completely abolished the rise in CAP hemolymph titers normally seen immediately after adult emergence (Tublitz and Truman, 1985b), indicating that antibody treatment was pharmacologically able to depress CAP levels. That this immunoneutralization effect is not simply due to a blockage of the cardiac peptide receptor is based on the results from preliminary experiments in which $\mathrm{CAP}_{2}$ activity was not diminished when applied on the in vitro heart bioassay that had bcen exposed to 6C5 (Tublitz, unpublished observations). 6C5 treatment also blocked most of the increase in heart rate seen during adult emergence and WS behaviors (Fig. 4, Table 1), clearly showing that the postemergence excitation of the Manduca heart in vivo is a physiological result of the elevated CAP levels. Moreover, antibody-treated animals without high levels of CAP in their hemolymph took much longer to inflate their wings successfully (Fig. 5). These results confirm our hypothesis that the primary function of the CAPs is to facilitate the successful completion of WS behavior by elevating beat frequency of the circulatory system. 
Are the CAPs responsible for all the changes in heart rate during eclosion and WS?

The behavior of the heart in pharate adult and adult Manduca is exceedingly complex (Tublitz and Truman, 1985b). Prior to adult emergence, the heart is characterized by 2 distinct alternating modes of activity, commonly known as heartbeat reversals. At emergence, heartbeat reversals cease, and there is an almost immediate rise in heartbeat frequency. Heart rate slowly declines during WS behavior, and heartbeat reversals resume only after the wings are fully inflated.

The results from the experiments described in this paper clearly indicate that the CAPs are not responsible for all of the postemergence changes in the behavior of the heart. Antibody application failed to prevent the termination of heartbeat reversals at eclosion and also did not completely inhibit the rise in heart rate (Fig. 4, Table 1). It is possible that the local release of the CAPs around the cardiac musculature was not accessible to the antibody procedure. Alternatively, the CNS might be responsible for these effects via direct neural innervation. The latter interpretation is corroborated by data from both this and previous studies (Tublitz and Truman, 1985b), which have shown that the peak CAP titers occur after heart rate has reached its maximal level. Studies in other insects (Heinrich, 1970, 1971) have clearly shown that the CNS plays an important role in the regulation of the heart. As the innervation of the lepidopteran heart is not well known at present, this hypothesis of direct neural control must await testing.

\section{Monoclonal antibodies as pharmacological tools}

It is clear that monoclonal antibodies have other uses besides their more established ones as cellular markers (Valentino et al., 1985). They have been utilized as physiological tools in recent studies on developing (Steinhart and Alderton, 1982), neurosecretory (Kenigsberg and Trifaro, 1985), and neuronal tissues (Lundberg, 1981). Here, we have shown that a specific monoclonal antibody to the CAPs is capable of blocking neuropeptide activity both in vivo and in vitro in the tobacco hawkmoth, $M$. sexta, under well-defined conditions. As demonstrated in this report, the advantages of monoclonal antibodies for pharmacological and physiological investigations should not be underestimated (Valentino et al., 1985), especially in cases where pharmacological blockers are difficult, if not impossible, to obtain (e.g., Hanley, 1982). The use of antibodies in these situations will surely enhance our ability to elucidate the physiological role played by neuropeptides and other neuroeffectors.

\section{References}

Abrams, T. W., V. F. Castellucci, J. S. Camardo, E. R. Kandel, and P. E. Lloyd (1984) Two endogenous neuropeptides modulate the gill and siphon withdrawal reflex in Aplysia by presynaptic facilitation involving cAMP-dependent closure of a serotonin sensitive potassium channel. Proc. Natl. Acad. Sci. USA 81: 7956-7960.

Adams, M. E., and M. O'Shea (1983) Peptide co-transmitter at a neuromuscular junction. Science 221: 286-289.

Barker, J. L. (1977) Physiological roles for peptides in the nervous system. In Peptides in Neurobiology, H. Gainer, ed., pp. 295-343, Plenum, New York.

Brownell, P., and E. Mayeri (1979) Prolonged inhibition of neurons by neuroendocrine cells in Aplysia. Science 204: 417-420.

Evans, P. D. (1981) Multiple receptor types for octopamine in the locust. J. Physiol. (Lond.) 318: 99-122.

Guillemin, R. (1978) Peptides in the brain. Science 202: 390-402.

Hanley, M. R. (1982) Substance P antagonists. Trends Neurosci. 5: $138-140$.

Heinrich, B. (1970) Nervous control of the heart during thoracic temperature regulation in a Sphinx moth. Science 169: 606-607.

Heinrich, B. (1971) Temperature regulation of the Sphinx moth, Manduca sexta. II. Regulation of heat loss by control of blood circulation. J. Exp. Biol. 54: 153-166.
Jan, L. Y., and Y. N. Jan (1982) LHRH-like peptide as a transmitter in sympathetic ganglion. Frontiers Neuroendocrinol. 7: 211-254.

Kenigsberg, R. L., and J. M. Trifaro (1985) Microinjections of calmodulin antibodies into cultured chromaffin cells block catecholamine release in response to stimulation. Neuroscience 14: 335-347.

Konishi, S., A. Tsunoo, and M. Otsuka (1981) Enkephalin as a transmitter for presynaptic inhibition in sympathetic ganglia. Nature 294 : 80-82.

Kreiger, D. T., M. Brownstein, and J. Martin, eds. (1983) Brain Peptides, Wiley, New York.

Kupfermann, I. (1970) Stimulation of egg-laying by extracts of neuroendocrine cells (bag cells) of abdominal ganglion of Aplysia californica. J. Neurophysiol. 33: 877-881.

Langer, S. Z. (1980) Presynaptic receptors and modulation of neurotransmission: Pharmacological implications and therapeutic relevance. Trends Neurosci. 3: 110-112.

Lloyd, P. E. (1978) Neurohormonal control of cardiac activity in the snail, Helix aspersa. J. Comp. Physiol. 128: 277-283.

Lloyd, P. E., I. Kupfermann, and K. R. Weiss (1984) Evidence for parallel actions of a molluscan neuropeptide and serotonin in mediating arousal in Aplysia. Proc. Natl. Acad. Sci. USA 81:2934-2937.

Lundberg, J. M. (1981) Evidence for co-existence of vasoactive intestinal polypeptide (VIP) and acetylcholine in neurons of cat exocrine glands: Morphological, biochemical and functional studies. Acta Physiol. Scand. Suppl. 496: 1-57.

Lundberg, J. M., T. Hökfelt, M. Schultzberg, K. Uvnas-Wallensten, C. Kohler, and S. I. Said (1979) Evidence of vasoactive intestinal polypeptide (VIP)-like immunoreactivity in certain cholinergic neurons of the cat: Evidence from combined immunohistochemistry and acetylcholinesterase staining. Neuroscience 4: 1539-1559.

Mayeri, E., and B. S. Rothman (1982) Nonsynaptic peptidergic transmission in the abdominal ganglion of Aplysia. In Neurosecretion: Molecules, Cells, and Systems, D. S. Farner and K. Lederis, eds., pp. 305-315, Plenum, New York.

Miller, T. A. (1973) Measurement of insect heartbeat by impedance conversion. Physiologist Teacher 2: 1-3.

Moreau, R., and L. Lavenseau (1975) Role des organes pulsatile thoraciques et du coeur pendant l'emergence et l'expansion des ailes des Lepidopteres. J. Insect Physiol. 21: 1531-1534.

Pfaff, D. W. (1973) Luteinizing hormone releasing factor potentiates lordosis behavior in hypophysectomized ovariectomized female rats. Science 182: 1148-1150.

Steinhart, R. A., and J. M. Alderton (1982) Calmodulin confers calcium sensitivity on secretory exocytosis. Nature 295: 154-155.

Taghert, P. H., N. J. Tublitz, J. W. Truman, and C. S. Goodman (1983) Monoclonal antibodies to insect peptidergic neurons. Soc. Neurosci. Abstr. 9: 314.

Taghert, P. H., N. J. Tublitz, C. S. Goodman, and J. W. Truman (1984) Monoclonal antibodies that recognize cardioactive peptides in the moth, Manduca sexta. Soc. Neurosci. Abstr. 10: 152.

Takahashi, T., S. Konishi, D. Powell, S. E. Leeman, and M. Otsuka (1974) Identification of the motoneuron-depolarizing peptide in bovine dorsal root as hypothalamic substance P. Brain Res. 73: 59-69.

Truman, J. W. (1980) Eclosion hormone: Its role in coordinating ecdysial events in insects. In Insect Biology in the Future, M. L. Locke and D. S. Smith, eds., pp. 384-401, Academic, New York.

Tublitz, N. J. (1983) The biochemical and physiological analyses of two cardioregulatory neuropeptides in the moth, Manduca sexta. Ph.D. dissertation, University of Washington, Seattle.

Tublitz, N. J., and J. W. Truman (1980) The physiology and pharmacology of the heart in the tobacco hawkmoth, Manduca sexta. Am. Zool. 20: 867.

Tublitz, N. J., and J. W. Truman (1985a) Insect cardioactive peptides: I. Distribution and molecular characteristics of two cardioacceleratory peptides in the tobacco hawkmoth, Manduca sexta. J. Exp. Biol. 114: 365-379.

Tublitz, N. J., and J. W. Truman (1985b) Insect cardioactive peptides: II. Neurohormonal control of heart activity by two cardioacceleratory peptides in the tobacco hawkmoth, Manduca sexta. J. Exp. Biol. 114: 381-395.

Tublitz, N. J., and J. W. Truman (1985c) Identification of the neurones containing cardioacceleratory peptides (CAPs) in the ventral nerve cord of the tobacco hawkmoth, Manduca sexta. J. Exp. Biol. 116: 395-410. 
Tublitz, N. J., and J. W. Truman (1985d) Intracellular stimulation of an identified neuron evokes cardioacceleratory peptide release in an insect. Science 228: 1013-1014.

Valentino, K. L., J. Winter, and L. F. Reichart (1985) Application of monoclonal antibodies to neuroscience research. Annu. Rev. Neurosci. 8: 199-232.

Wasscrthal, L. T. (1976) Hcartbeat reversal and its coordination with accessory pulsatile organs and abdominal movements in Lepidoptera. Experientia 32: 577-579.
Werman, R. (1966) Criteria for identification of a central nervous system transmitter. Comp. Biochem. Physiol. 18: 745-766.

Wigglesworth, V. B. (1972) The Principles of Insect Physiology, 7th ed., p. 422, Chapman and Hall, London.

Williams, C. M. (1959) The juvenile hormone. I. Endocrine activity of the corpora allata of the adult cecropia silkworm. Biol. Bull. 116: 323-328. 